\title{
More on NDEs and Satisfaction with Life
}

To the Editor:

Of the many interesting articles in recent issues of the Journal, the most intriguing by a long way for me was Bruce Greyson's (1994) very discreet entry into Susan-Blackmore-type territory with his paper showing that the much-publicized positive aftereffects of neardeath experiences (NDEs) apparently do not lead to any above-average long-term life satisfaction. For all his gentle manner of presentation, and quiet suggestion that his findings may be explained in terms of NDErs' difficulties in readjusting to practical life, he must surely have set several cats amongst the proverbial pigeons. His findings came as no surprise to me, however, and this despite (a) having myself enjoyed very greatly increased life satisfaction ever since my own 1983 NDE (Wren-Lewis, 1985, 1994) and (b) having urged, in my Guest Editorial for the Journal (Wren-Lewis, 1992) that the major significance of the NDE phenomenon lies in demonstrating the possibility of a mystical dimension of consciousness in this life rather than in providing evidence that personal consciousness may survive bodily death.

A subtheme of my own research over the past decade has been an investigation of why no other NDE report in the literature (to my knowledge) has mentioned bringing the timeless heavenly peace and happiness of the experience itself back, undiminished, into subsequent daily life after resuscitation, as happened with me. In other words, I've been trying to understand why the "mystical opening" that Kenneth Ring (1984) identified as a common feature of NDEs doesn't last, except as an inspiring memory that often motivates NDErs into a life of spiritual work and search.

My own continuing day-by-day (and night-by-night) "eternity-experience" since 1983 disproves the common assumption that such consciousness is a very high state to be achieved only by a long struggle of spiritual practice and purification. In fact, my experience suggests that this assumption is part of the very mindset that has kept humanity in general locked into the petty pace of time (with very low life satisfaction) for most of its history. My conclusion (Wren-Lewis, 1994) is that the "eternity-consciousness" of the mystics is in fact the truly natural human condition, blocked out by something like a hyperactivity of the mind's survival programs, passed on by conditioning from one generation to the next. 
The mystical openings in NDEs occur because those programs relax at the point of death, but as I demonstrate in my forthcoming book The 9:15 to Nirvana (Wren-Lewis, in press), they are normally aborted on resuscitation by the deeply-ingrained common mindset that consciousness in earthly life must necessarily be timebound. The mindset, sometimes actually personified in near-death visions as heavenly command to "return to earth," has the effect of converting the eternity-opening into a wonderful but temporary experience of the timebound personality.

Greyson's findings jibe very well with this model of the NDE, but the significance of his report will be lost if it becomes the occasion either for skeptical dismissal of NDEs as mere passing mental aberrations or for attempts to explain his findings away in order to retain the mystique of NDEs. As I see it, Greyson's study indicates the most important challenge to be faced on this vital research frontier: the challenge of unearthing the mechanisms responsible for the common human conditions of eternity-blindness. And the fact that those mechanisms can be seen in operation when NDE-breakthroughs get lost in return to timebound life may be the best clue yet to understanding and outwitting them.

\section{References}

Greyson, B. (1994). Near-death experiences and satisfaction with life. Journal of NearDeath Studies, 13, 103-108.

Ring, K. (1984). Heading toward omega: In search of the meaning of the near-death experience. New York, NY: Morrow.

Wren-Lewis, J. (1985). The darkness of God: An account of lasting mystical consciousness resulting from an NDE. Anabiosis: The Journal of Near-Death Studies, 5(2), 53-66.

Wren-Lewis, J. (1992). Avoiding the Columbus Confusion: An Ockhamish view of neardeath research. Journal of Near-Death Studies, 11, 78-81.

Wren-Lewis, J. (1994). Aftereffects of near-death experiences: A survival mechanism hypothesis. Journal of Transpersonal Psychology, 26, 107-115.

Wren-Lewis, J. (In press). The 9:15 to Nirvana.

John-Wren Lewis

1/22 Cliffbrook Parade Clovelly, New South Wales Australia 2031 